\title{
A GENERALIZED PETRI NET-BASED DIAGNOSER FOR FAULT DETECTION AND ISOLATION IN COMPLEX PROCESSES
}

\author{
Hamdi A. Awad \\ Dept. of Industrial Electronics and Control Eng., Faculty of Electronic \\ Eng., Menouf, 32952, Menoufia University, Egypt \\ Awadhaa@yahoo.co.uk
}

(Received May 20, 2009 Accepted June 18, 2009)

\begin{abstract}
Recently, an efficient method for obtaining reduced interpreted Petri net, $I P N$, diagnoser was previously proposed for discrete event systems. This diagnoser consists of a single place and the same number of transitions that the system model has. Although, the current marking of this place (diagnoser) is enough to determine and locate faults occurring in a simple diagnosable discrete event system, it fails to determine and locate faults occurring in a complex non-diagnosable hydride systems that have discrete and continuous variables. Diagnosability means that the PN model is live, strongly-connected, and Transition-invariant (T-invariant); however, most of PN models are not diagnosable. This paper generalizes the IPN-based diagnoser to deals with such complex systems with ease. Chemical batch processes are employed to test the modified IPN-based diagnoser and the simulation results obtained indicate that the proposed diagnoser is promising for industrial processes.
\end{abstract}

KEYWORDS: Discrete event systems, Hybrid systems, Fault detection and isolation, Petri nets, Interpreted Petri Nets, Chemical batch processes.

\section{INTRODUCTION}

In general, modern technological processes include complex and large scale systems, where faults in a single component have major effects on the availability and performances of the system as a whole. Faults can be due to internal events as to external ones. Hybrid systems modeling and supervision have been used extensively in automation, and manufacturing applications that includes such faults [1]. Different frameworks for dynamic supervisory controllers are used in flexible manufacturing systems and automated batch processes [2-3]. The high-level system changes in hybrid systems are modeled as discrete event dynamic systems, while the low-level systems changes are modeled as continuous variable dynamic systems. The major issue in studying hybrid systems is the consistency between continuous and discrete models evolution.

Fault detection is the central component of abnormal event management (AEM), which deals with the detection, diagnosis and correction of faults in hybrid systems. Many authors addressed the technical challenges in research and development that need to be directed for the successful design and implementation of practical 
intelligent supervisory control systems for the process industries. They classified the FDI different methods into three categories [4-5]: Quantitative model-based methods, Qualitative model -based methods, and Process history based methods. In fact, these diagnostic methods are computationally demand.

Petri nets possess many assets as models for discrete event systems DES. Concurrent processes and events can be easily modeled within this framework. As a powerful modeling formalism, PNs aiming to avoid the state explosion problem of large discrete systems. They provide more compact representation for larger reachable state spaces, and increase the behavioral complexity compared with automata-based models [6-7]. An efficient method for obtaining a diagnoser interpreted Petri net (IPN) model was proposed for DES systems [8]. This model consists of a single place and the same number of transitions that the system model has. However, this diagnoser has some limitations when it is employed for hybrid systems. The main objective of this paper is to generalize the IPN diagnoser to locate and isolate faults in such systems.

The main contribution of this paper can be summarized as follows:

1- Generalizing the IPN-based diagnoser to deals with hybrid complex systems.

2- Avoiding the restrictions of diagnosablity property at PN models

3- Testing the proposed scheme on the complex batch processes

The rest of the paper is organized as follows. Section 2 presents the basic concepts and notation of PN and IPN. Section 3 generalizes the conventional IPNbased diagnoser. Section 4 reports the results obtained from detecting and isolating faults in chemical processes using the generalized diagnoser. The topics in this paper by summarizing the contributions made and presenting suggestions for future research are concluded in section 5 .

\section{THE BBASIC CONCEPTS AND NOTATIONS OF PN AND IPN}

This section presents the basic concepts and notation of PN and IPN used in this paper. For more details the reader can be directed to read [6-9].

A Petri net is a particular kind of bipartite directed graphs populated by three types of objects. These objects are places, transitions, and directed arcs. Directed arcs connect places to transitions or transitions to places. In its simplest form, a Petri net can be represented by a transition together with an input place and an output place. This elementary net may be used to represent various aspects of the modeled systems. In order to study the dynamic behavior of a Petri net modeled system in terms of its states and state changes, each place may potentially hold either none or a positive number of tokens. Tokens are a primitive concept for Petri nets in addition to places and transitions. The presence or absence of a token in a place can indicate whether a condition associated with this place is true or false.

IPNs are a special kind of PNs. Compared with the latter, the former is simpler and faster for detecting and isolation faults in discrete event systems. Definitions and notations that are needed for this work can be briefly described below.

Definition 1: A Petri Net structure $G$ is a bipartite digraph represented by the 4-tuple as defined in (1):

$$
G=(P, T, I, O)
$$


where: $P=\{p 1, p 2, \ldots, p n\}$ and $T=\{t 1, t 2, \ldots, t m\}$ are finite sets of vertices named places and transitions respectively, $I(O): P \times T \rightarrow Z^{+}$is a function representing the weighted arcs going from places to transitions (transitions to places); $Z^{+}$is the set of nonnegative integers. Pictorially, places are represented by circles, transitions are represented by rectangles, and arcs are depicted as arrows. The symbol ${ }^{*} t_{j}\left(t_{j}^{\bullet}\right)$ denotes the set of all places pi such that $I\left(p_{i}, t_{j}\right) \neq 0 \quad O\left(p_{i}, t_{j}\right) \neq 0$. Analogously, ${ }^{*} p_{i}\left(p_{i}^{*}\right)$ denotes the set of all transitions $t j$ such that $O\left(p_{i}, t_{j}\right) \neq 0 \quad\left(I\left(p_{i}, t_{j}\right) \neq 0\right)$. The incidence matrix of $G$ is $C$. A marking function $M: P \rightarrow Z^{+}$represents the number of tokens (depicted as dots) residing inside each place. The marking of a PN is usually expressed as an $n$-entry vector.

Definition 2: An IPN is a class of PNs. It is defined in (2):

$$
I P N=\left(\mathrm{Q}, M_{0}\right)
$$

The IPN structures with $\mathrm{Q}=(\mathrm{G}, \Sigma, \lambda, \varphi$,$) and an initial marking M_{0}$. Where $\square \mathrm{G}$ is a PN structure, $\Sigma=\{\alpha 1, \alpha 2, \ldots, \alpha r\}$ is the alphabet of input symbols $\alpha \mathrm{i}, \lambda$ : $\mathrm{T} \rightarrow \Sigma \sum \cup\{\varepsilon\}$ is a labeling function of transitions with the following constraint: $\forall t_{j}, t_{k} \in T, j \neq k$, if $\forall p_{i} I\left(p_{i}, t_{j}\right)=I\left(p_{i}, t_{k}\right) \neq 0 \quad$ and both $\lambda\left(t_{j}\right) \neq \varepsilon, \lambda\left(t_{k}\right) \neq \varepsilon$, then $\lambda\left(t_{j}\right) \neq \lambda\left(t_{k}\right) ; \varepsilon \square$ represents a system internal event, And $\varphi: R\left(Q, M_{0}\right) \rightarrow\left(Z^{+}\right)^{q}$ is an output function, that associates to each marking in $\mathrm{R}\left(\mathrm{Q}, M_{0}\right) q$-entry output vector; $q$ is the number of outputs.

A fault detection and isolation using conventional IPN-based diagnosers was proposed in [8]. It consists of a single place and the same number of transitions that the discrete event system has. In this model, the current marking of this place is enough to determine and locate faults occurring within a discrete event system. When $e_{k}=0$, an error is detected, and then a faulty marking was reached. The mechanism used to find out the faulty marking is named fault isolation. The main problem of the use of such model is that its limitation to detect and isolate faults in simple diagnosable processes with single-input and single-output transitions shown in Fig. 1. Diagnosability means that the PN model is live, strongly-connected, and T-invariant. The latter indicates that if it is possible to fire the given set of transitions, in any order, the state of the net will return to its initial condition at the end of the sequence. Unfortunately, most of PN models are not diagnosable. Moreover, consider a mixer in a complex chemical reactor depicted in Fig. 2 has MIMO transitions e.g. $T_{m 5}$ and $T_{m 6}$ respectively. The conventional IPN-based diagnoser may fail to locate and isolate faults for such systems as will be depicted in section 4 . To overcome this problem, this paper generalizes the IPN-based diagnosers in section 3.

\section{THE GENERALIZED IPN-BASED DIAGNOSER}

This section describes the conventional IPN-based diagnoser, the problem statement, and the generalized IPN-based diagnoser. 


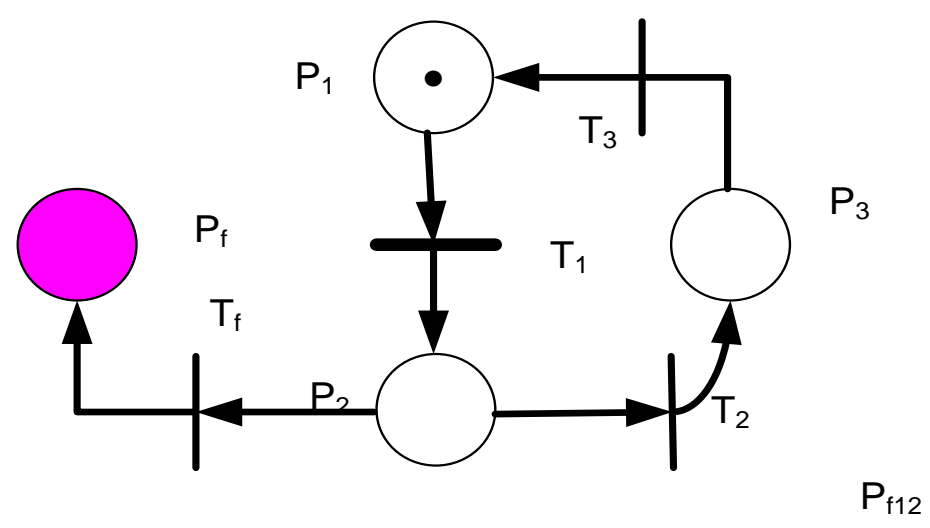

Figure 1

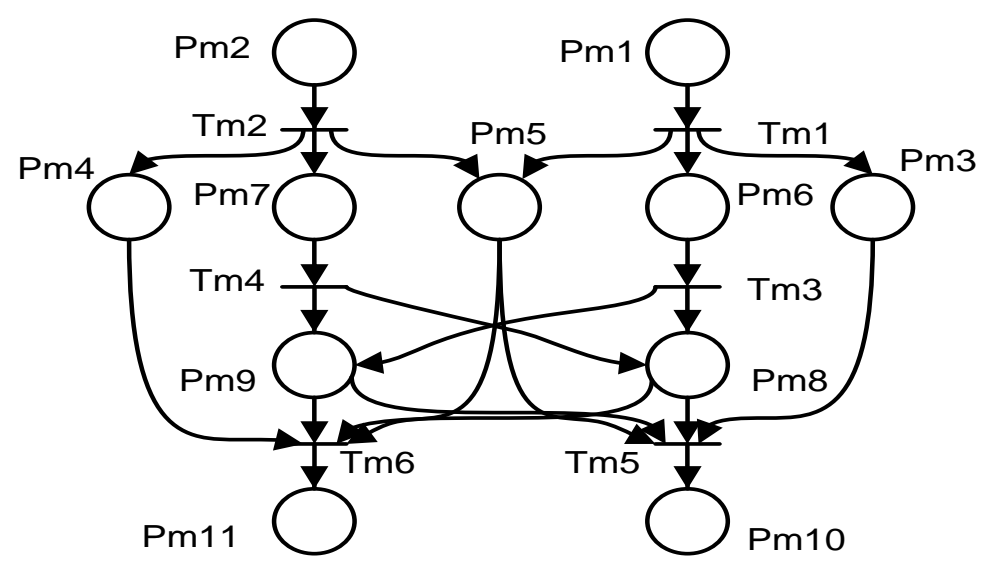

Figure 2: Mixing tank PN-model

\section{A. The conventional IPN-based diagnoser}

Figure 3 shows the connections of the conventional IPN-based diagnoser, D, with the normal transitions. The weight wi is ith content of the incident matrix $C^{d}$ defined as [8]:

$$
C^{d}=B^{T} \phi^{T} \phi C^{N}
$$

where $B$ is $n x l$ vector with internal elements $x$ that can be computed using the exponential base, $b$. That is $b=\operatorname{MAX}[a b s(C i j)]+1$ and $x=b i$, where, $i$ is an integer numbers, $1,2, \ldots$, for the measurable places, and $\mathrm{x}=0$ for nonmeasurable places. The matrix $\phi$ is qxn output matrix where, $q$ is the measurable outputs, and $n$ is the number of places. The matrix $C_{N}$ is nxm matrix that describes the normal process. The $i^{\text {th }}$ transition is $T_{i}$ as shown in the figure. The parameter $a$ and $b$ are the alphabet of the input symbols that represents the external input of the system, and $\varepsilon$ represents the internal input of the system. 


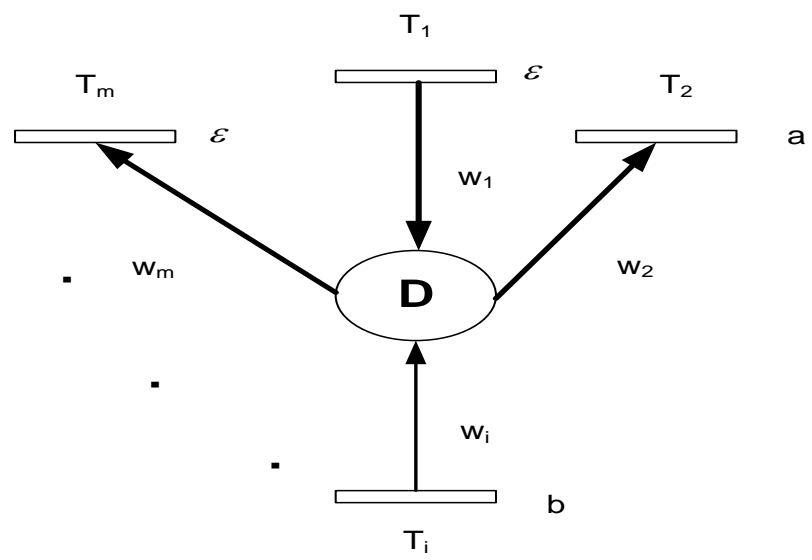

Figure 3

Algorithm-1: The conventional IPN-based diagnoser is listed below.

Inputs: $M_{k}, M_{k}^{d}, e_{k}$; where, $M_{k}$ is the marking vector of the normal process, $M_{k}^{d}$ is the marking place of the diagnoser, and ${ }^{e_{k}}$ is the error between them.

Outputs: $\mathrm{p}$ (faulty place), $M_{f}$ (faulty marking) and Constants: $C^{d}$ is the IPN diagnoser structure incidence matrix defined in (3).

$i$ is the index of the column of $C^{d}$ such that $C^{d}(1, i)=e k$

1- $\forall p \in t_{i}, M_{k}(P)=0$

2- $\forall p \in t_{i}, M_{k}(P)=0$

3- $\forall p^{F} \in\left(t_{i}\right) \cdots \cap P^{F}, M_{k}\left(p^{F}\right)=1$

$4-M_{f}=M_{k}$

5 - Return $\left(p, M_{f}\right)$

\section{B. Problem statement, motivations and contributions}

The conventional IPN-based diagnoser can determine and locate faults occurring within a discrete event system that has transitions with single-input and single-output (SISO) as shown in Fig. 1. However, it fails to determine and locate faults occurring within a complex hydride control systems that have multi-input and multi-output transitions (MIMO) depicted in Fig. 2. The reason for this shortcoming is that the diagnoser incidence matrix $C^{d}$ should have columns are not null and different from each other, however, for complex systems this incidence matrix may has null and similar values. That is why the diagnoser is not applicable for all PN models.

The key solution of that problem is that the diagnoser should check faulty marking place $M_{k}\left(p^{F}\right)$ as well as the diagnoser incident matrix $C^{d}$ as depicted in 
the generalized IPN-based-diagnoser shown in Fig. 4 for detecting the faults of the undetectable transitions. The normal and faulty marking vectors respectively, should be updated every time step.

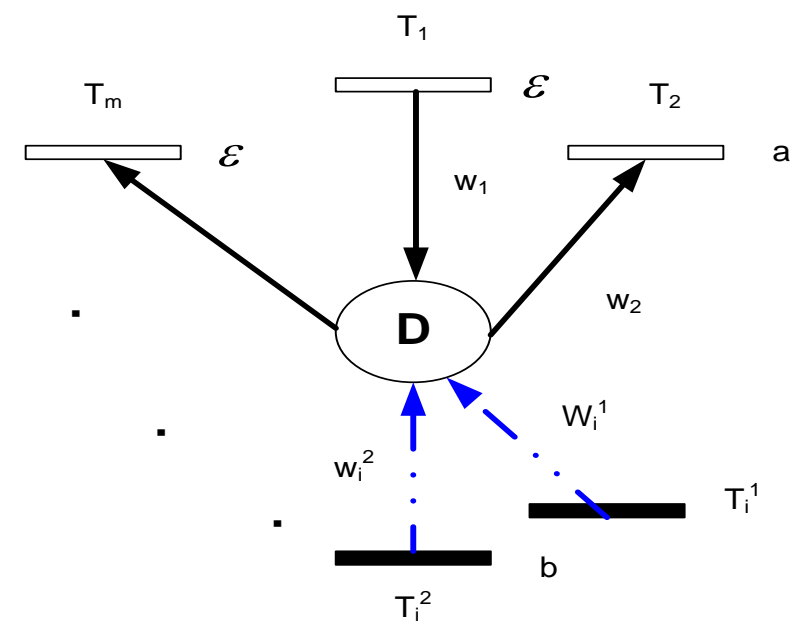

Figure 4

\section{The generalized IPN-based diagnoser}

Algorithm-2: The generalized IPN-based diagnoser is proposed as follows. Inputs: $M_{k}, M_{k}^{d}, e_{k} \quad$ These variables are described in the algrothem-1. Outputs: $p^{F}$ is the faulty place, and $M_{f}$ is the faulty marking

Constants: $C^{d}$ is the IPN diagnoser incidence matrix

$\mathrm{i}=$ index of the column of $C^{d}$ such that $C^{d}(1, i)=e k$

1- $\forall p \in t^{\bullet}, M_{k}(P)=0$

2- $\forall p \in t_{i}, M_{k}(P)=0$

3- $\forall p^{F} \in\left({ }^{\bullet} t_{i}\right)^{\bullet} \cap P^{F}, M_{k}\left(p^{F}\right)=1$

4- updating the faulty and normal marking vectors

$M_{n}(k+1)=M_{n}(k)+C_{n} Z$

$M_{f}(k+1)=M_{f}(k)+C V$

where $Z$ and $V$ are respectively, the input vectors of the system. $C$ and $C n$ are the incidence mantises of the diagnoser at normal and faulty operation respectively. So, this paper generalizes the conventional IPN-based diagnoser listed in subsection A as follows.

To compute the weights of the multi-input muti-output transition shown in Fig. 4 , this paper proposes the following routine. 
5- If $e_{k}$ not equals any value in the matrix $C^{d}$ Then apply the following proposed routine:

A- Define the ith position of the faulty place using, $M_{k}(i, 1)=-\tau$ where $\tau$ is the number of moved tokens, and the negative sign indicates that the faulty marking place losses token unlike the normal marking vector.

B- Define the jth position of the faulty place using, $C(I, j)=-\tau$ at the $\mathrm{i}^{\text {th }}$ position of the faulty place, I.

C- To detect the faulty place, firstly, compute $X(i, 1)=\left(\sum_{i} C_{J}\left(., J_{1}\right) \cup C_{J}\left(., J_{2}\right)\right)$, Then $P^{F}=X(I, 1)=\kappa$, where

$\kappa$ is a positive integer that represents the link between the faulty place and its transition.

D- Return (p, $\left.M_{f}\right)$

Else: $M_{f}=M_{k}$ and finally Return (p, $M_{f}$ )

This modification enables the generalized dignoser to detect the faulty place for non-diagnosable processes, unlike the conventional IPN-based diagnoser as will be shown from the simulation results.

\section{SIMULATION RESULTS OF THE GENERALIZED IPN DIAGNOSER}

Batch processes, automation and optimization, pose difficult problems because it is necessary to operate concurrently with continuous (algebraic or differential equations) and discrete (Petri net) models. They consist of many transport resources (transporters) like valves and pipes, and processing resources (processors) like mixing tanks, batch reactor vessels, and other container like units [9-10]. This complex structure has many expected faults that should be located and isolated. Researches have been conducted for this issue; however, they are computationally demand. Chetouani presented a FDI strategy for nonlinear dynamic systems [2]. It shows a methodology of tackling the fault detection and isolation issue by combining a technique based on the residuals signal and a technique using the multiple Kalman filters. This paper proposes a simpler, but effective, enhanced IPN-based doiagnoser for such complex hybrid systems. The structure and the PN model of the batch process to be used in this paper and its supervisor have been proposed in [9] and it can be briefly described in subsection A. Fault detection and isolation of the batch process using the conventional and enhanced IPN-based are discussed in subsection B. 


\section{A. The system description}

The employed chemical batch process cell is described in this subsection. Two mixing tanks share the same supply tank. Mixing tanks are repeatedly filled and discharged with the restriction that only one tank can be filled at a time as shown in Fig. 4. It represents the final stage of large scale chemical batch process [9].

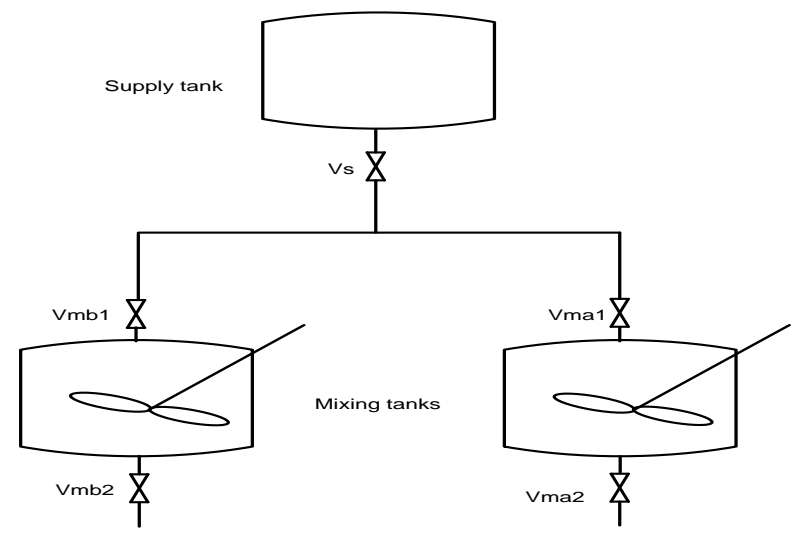

Figure 4: Batch process cell with two reactors.

The basic recipe for the reactor is given in Table 1.

Table 1. Illustration of places and transitions for each sub model.

\begin{tabular}{||l|l||}
\hline Place & Associated Action \\
\hline \hline Pm1 & Process ready. \\
\hline Pm2 & Open the inlet valve of the mixing tank. \\
\hline Pm3 & Open the valve of supply tank. \\
\hline Pm4 & Stir the content of mixing tank. \\
\hline Pm5 & $\begin{array}{l}\text { Discharge the mixing tank (Open the outlet } \\
\text { valve) }\end{array}$ \\
\hline \hline Transition & Associated Event \\
\hline \hline Tm1 & Start a new batch. \\
\hline Tm2 & Mixing tank is filled. \\
\hline Tm3 & Duration of mixing operation is vanished. \\
\hline Tm4 & Mixing tank is emptied. \\
\hline \hline
\end{tabular}

The PN model of this chemical batch process and its supervisor is depicted in Fig. 5 [9]. The readers who are interested in modeling and supervision of such processes are referred to [8-13]. 


\section{B. Simulation Results}

\section{B.1- A system testing using the conventional IPN-based diagnoser}

Considering the PN model of the Fig. 6, which represent the behavior of a system. This model is diagnosable [8], thus a diagnoser for this net can be built using the structure shown in Fig. 3 and its incidence matrix, $C^{d}=\left[\begin{array}{llllll}-7 & -3 & 1 & 27 & -1 & 8\end{array}\right]$, has different and non zero values.

At firing the 1st transition, the output of the IPN-based process model, $y(k)=3$, and the output of the IPN-based diagnoser, $y d=3$, and the difference between them, $\mathrm{e}(\mathrm{k})=0$. Compared this error with the contents of the incidence matrix $C^{d}$, the diagnoser indicates no fault.

At firing the 4th transition, the output of the IPN-based process model, $y(k)=3$, and the output of the IPN-based diagnoser, $y d=30$, and the difference between them, $e(k)=27$. Compared this error with the contents of the incidence matrix $C^{d}$ defined above, the diagnoser indicates a fault happened at event number 4 and the faulty place is its output; $p_{9}$.

\section{B.2- Chemical batch processes testing using the conventional IPN- based diagnoser}

Applying the same procedure for detecting and isolating the faults on the batch chemical process described in section 4 using the PN model shown in Fig. 5, results the following.

At firing the 1th transition, the output of the IPN-based process model, $y(k)=4$, and the output of the IPN-based diagnoser, $y d=4$, and the difference between them, $\mathrm{e}(\mathrm{k})=0$. The diagnoser indicates no fault happened.

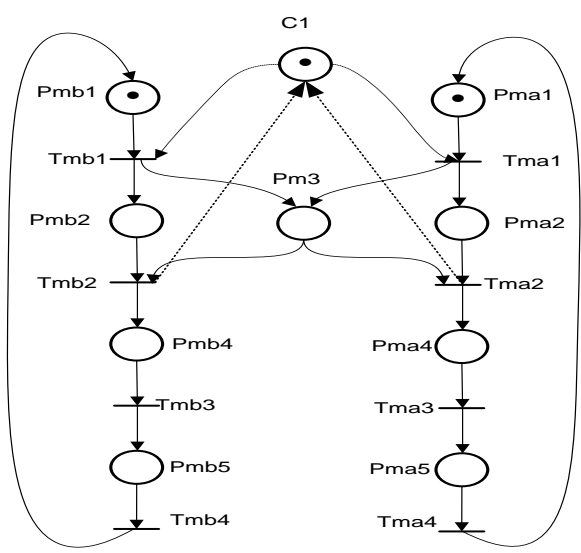

Figure 5: A unified plant/supervisor of the batch process 


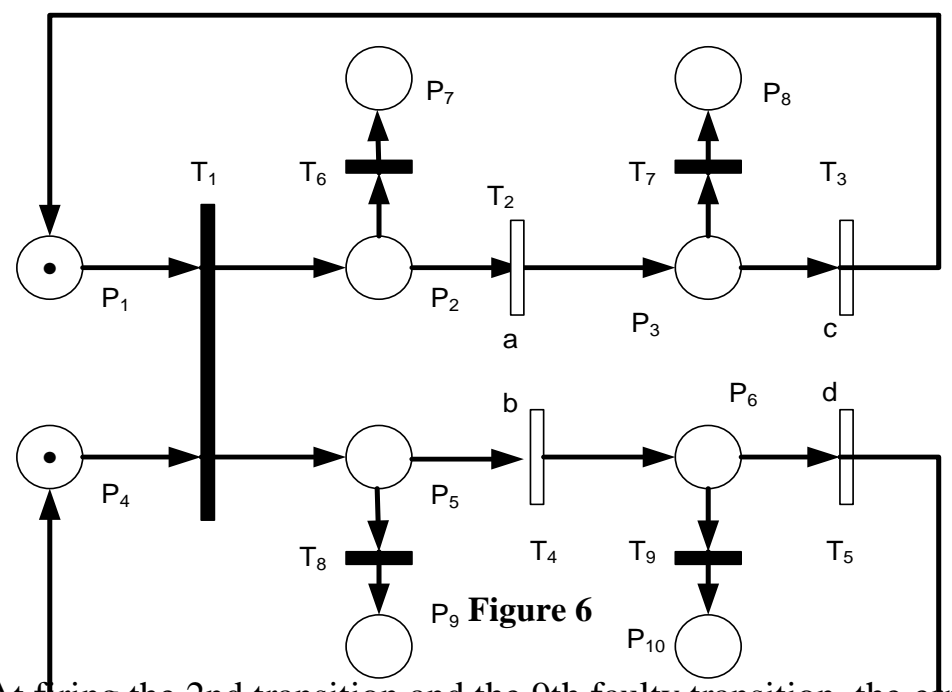

At flring the 2 nd transition and the 9 th faulty transition, the error, $\mathrm{e}(\mathrm{k})=5$. The diagnoser should indicate that the faulty place is $P_{f 11}$ only, however, its outputs two faulty places, $P_{f 11}$, and $P_{f 12}$ respectively as shown in Fig. 7 that shows a part of the whole PN model depicted in Fig. 5. This means that, the conventional diagnoser confused between the faulty place $P_{f 11}$, and the normal place $P_{f 12}$ as shown in the figure. This can be investigated using the diagnoser equation, $\forall p^{F} \in\left({ }^{\bullet} t_{i}\right) \cdot \bullet P^{F}, M_{k}\left(p^{F}\right)=1$, that includes the places $P_{f 11}$ and $P_{f 12}$ respectively as a subset of the general set that should intersected with the set of faulty places, $P^{F}$. This is totally wrong because the transition $T_{10}$ is not fired. It is clear that the conventional IPN-based diagnoser failed to determine and locate faults occurring within complex hydride systems (non diagnosable process) that have transitions multiinput and multi-output transitions (MIMO) depicted in Fig. 7.

For clarity reasons, let $(Q, M O)$ be an IPN diagnoser such that it is live, strongly connected and detectable then the diagnoser is diagnosable [11]. Diagnosability, means the diagnoser can be built. Sufficient conditions for diagnosability of DES modeled as Petri net are given in [14]. Because not all the PN models are diagnosable, this paper can conclude that the conventional IPN-based diagnoser is not applicable to all types PNs. This problem has been sorted out using the generalized IPN-based diagnoser proposed in section 3. Its simulation results are discussed in the following subsection.

\section{B.3- Chemical batch processes testing using the generalized IPN- based diagnoser}

The proposed IPN-based diagnoser has been tested using the batch process described in section 4 , at the same conditions of using the conventional IPN-based diagnoser and the simulation results are described as follows.

At firing the 1th transition, the output of the IPN-based process model, $y(k)=4$, and the output of the IPN-based diagnoser, $\mathrm{yd}=4$, and the difference between them $\mathrm{e}(\mathrm{k})=0$. The diagnoser indicates no fault happened. 


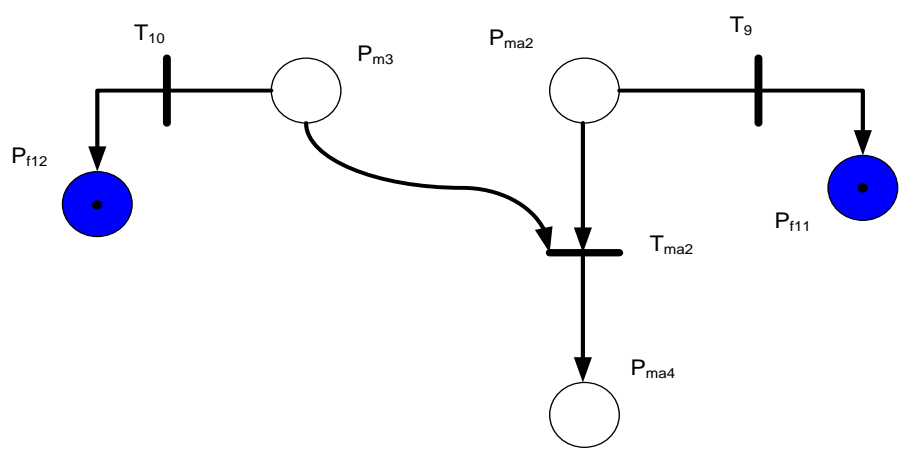

Figure 7

At firing the $2^{\text {nd }}$ transition and the $9^{\text {th }}$ faulty transition, the error, $\mathrm{e}(\mathrm{k})=1$. Unlike the conventional IPN-based diagnoser, the generalized diagnoser indicates that the faulty place is $P_{f l l}$ shown in Fig. 8. This is due to the virtue of using the current faulty marking with the proposed diagnoser to discriminate between the faulty states (places). The current faulty marking in the proposed diagnoser is enough to determine and locate faults occurring within a hybrid system not only that has SISO transitions but also that has MIMO transitions.

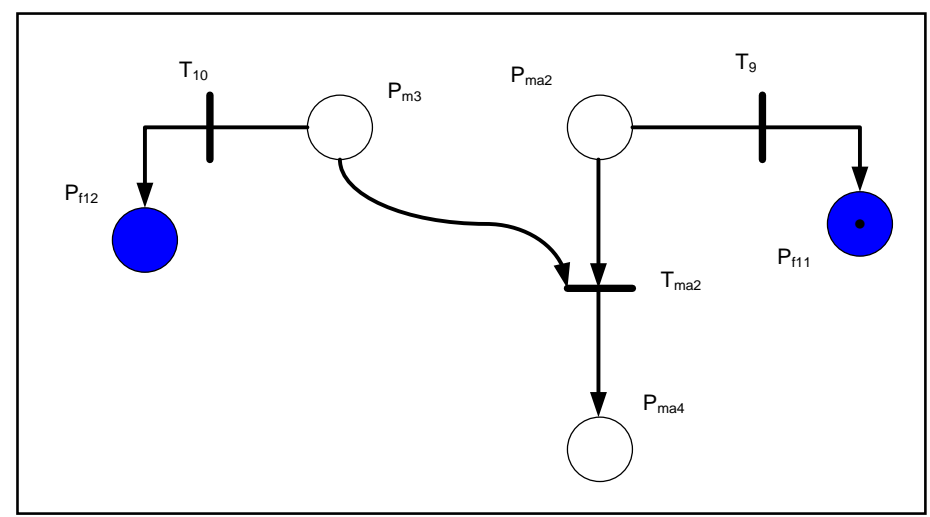

Figure 8

\section{CONCLUSIONS AND FUTURE WORK}

The main problem inherent to fault detection and isolation in batch processes is due to its hybrid nature. State variables like the tank level or the pump speed are continuous, others like the on-off valves, are discrete-state components. Model-based fault detection methods were proposed to detect and isolate faults in such systems; however, these models are computationally demand. This paper generalized IPN-based diagnoser to locate and isolate faults in hybrid dynamic systems with ease. Compared with the model-based methods, the generalized diagnoser is simpler, more effective, and faster. Also, unlike the conventional IPN-based diagnoser, simulation results reflected that the proposed diagnoser is promising for fault detection and isolation for all PN models that represents non-diagnosable and hybrid systems. 


\section{REFERENCES}

1. Gomaa M. M., Awad H. A., and Anwar A. R. "Design and Implementation of Supervisory Control Schemes in Industrial Automation Systems", The 2008 International Conference on Computer Engineering \& Systems (ICCES'08), pp. 389-404, Cairo, Egypt, 2008.

2. Chetouani Y. "Design of a Multi-Model Observer-based Estimator for Fault Detection and Isolation (FDI) Strategy: Application to a chemical reactor", Brazilian Journal of Chemical Engineering, ISSN 0104-6632, vol. 25, pp. 777 - 788, 2008.

3. Pepyne D. L, and Cassandras C. G. "Optimal control of hybrid systems in manufacturing", Proceedings of the IEEE, vol. 88, pp. 1108-1123, 2000.

4. Ho Yu-Chi., DEDS analyzing complexity and performance in the modern world. IEEE Press ,ISBN 0-87942-281-5, 1992.

5. Venkatasubramanian V., Rengaswamy R., Kavuri S. N., and Yin K. "A review of process fault detection and diagnosis. Part I: Quantitative model-based methods", Computers and Chemical Engineering, vol. 27, pp. 293-311, 2003.

6. Murata ] T., "Petri net: Properties, analysis, and applications", Proceedings of the IEEE, vol. 77, pp. 541-580, 1989.

7. Wonham W. M., "Supervisory control of discrete event systems", Systems Control Group, Dept. of ECE, University of Toronto, ECE 1636F/1637S, 2007.

8. Arámburo-Lizárraga J., Ramírez-Treviño A., López-Mellado E. , and RuizBeltrán E., Fault Diagnosis in Discrete Event Systems using Interpreted Petri Nets: Advances in robotics, automation and control. Book edited by: J. Arámburo and A. Ramírez-Treviño, ISBN 78-953-7619-16-9, pp. 472, October 2008, I-Tech, Vienna, Austria.

9. Ragab A., Modeling and supervision of discrete event systems. Ph.D. Thesis, Faculty of Electronic Eng., Menofia Unv., Egypt, 2007.

10. Falkman P., Lennartson B., Tittus M. "Specification of a Batch Plant using Process Algebra and Petri Nets", Proceedings of the IEEE International Conference on Automation Science and Engineering, Edmonton, Canada, pp. 339- 344 , August 2005.

11. Ramírez-Treviño A., Rivera-Rangel I., and López Mellado E., “Observability of Discrete Event Systems Modeled by Interpreted Petri Nets", IEEE Transactions on Robotics and Automation, vol. 19, pp. 557-565, 2003.

12. Andreu D., Pascal J. C., Pingaud H., Valette R., "Batch process modeling using Petri nets", IEEE Internattional Conference on Systems, Man and Cybernetics, San Antonio, USA, pp.314-319, October 1994.

13. Xi Z., "Modeling, Control, Fault Detection and Isolation of Chemical Processes using a Bond Graph Framework", Chemical Engineering, Texas Technology University, 2009.

14. Basile F., Chiacchio P., De Tommasi G., "An Efficient Approach for Online Diagnosis of Discrete Event Systems", IEEE Transaction on Automatic Control, vol. 54, pp. 748-759, 2009. 


\section{مشخص عام معتمدا علي شبكات بتري لاكتشاف الأعطال وعزلها}

\section{في العمليات المعقدة}

في الآونـة الأخيرة ظهرت طريقة فعالـة لاكتشـاف الأعطال وعزلها معتمدا على شبكات بتري تسمي وذلك لنظم الحدث المنفصلة البسيطة والتي يشترط فيها أن تكون قابلة لبناء كاشف لأعطالها (diagnosable). وشبكات بتري هذه تتكون من عدد من أل (itaces) وآخر

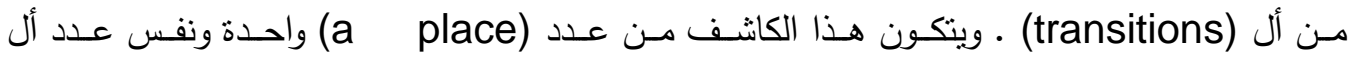
المستخدم لبنـاء نــوذج النظـام المعتمــ علي شبكات بتري. بـالرغم مـن فعاليـة هذا الكاثف من اكتثاف الأعطال وعزلها في النظم الني يتحقق فيها خاصية (diagnosability) الا انه فنشل في تحديد وعزل الأعطال للنظم التي لا يتحقق فيها هذه الخاصية (non-diagnosable) . يقترح هذا البحث تعميم وتطوير هذا الكاثف (A generalized IPN-based diagnoser) للتعامل ليس فقط مع الأنظمة الأخيرة فقط ولكن أيضا مع النظم المهجنة (Hybrid systems) والني

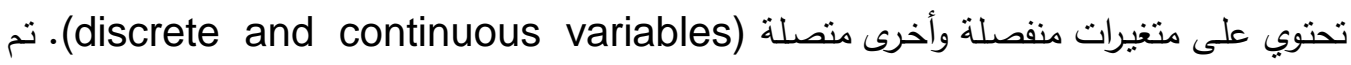
استخدام النظم الكيميائية لاختبار الكاشف المطور حيث أوضحت النتائج المحاكية فعالية هذا الكاشف في معالجة قصور الكاشف التقليدي.

Dr. Hamdy Ali Ahmed Awad received the B.Sc. degree in Industrial Electronics, and the M.Sc. degree in Adaptive Control Systems from Faculty of Electronic

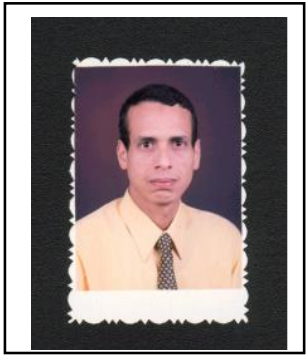
Engineering, Menouf, Menoufia University, Egypt in 1988 and 1994 respectively.

Dr. Awad received the Ph.D. degree in Artificial Intelligent Systems in 2001 from School of Engineering, Cardiff University, Cardiff-Wales, England.

Dr. Awad has got Associative Prof. degree in Computer Sciences and Control Systems in 2007. Since August 2007, he has been with the Faculty of Electronic Engineering, Menofia University, Egypt.

Dr. Awad interests in intelligent control systems, machine learning, and their applications in control systems, mechatronics, fault diagnosis and medical engineering. 